\title{
Mopping of crude oil and some refined petroleum products from the environment using sawmill factory waste: adsorption isotherm and kinetic studies.
}

\author{
KELLE, HI \\ Department of Pure and Applied Sciences, National Open University of Nigeria, Abuja, Nigeria \\ Corresponding Author: henriettachima@yahoo.com
}

\begin{abstract}
The oil (crude oil, diesel and kerosene) sorption capacity, sorbed oil recoverability and retainability by sawdust was determined under the same experimental condition and compared with that of a standard. The result of the study shows that the sawdust has lesser oil sorption capacity and sorbed oil recoverability than the standard, but higher sorbed oil retainability than the standard. Sawdust sorbed per unit mass $5.50 \mathrm{~g}$ of crude oil, $4.50 \mathrm{~g}$ of diesel and $4.20 \mathrm{~g}$ of kerosene while the standard sorbed per unit mass $11.50 \mathrm{~g}$ of crude oil, $10.35 \mathrm{~g}$ of diesel and $8.20 \mathrm{~g}$ of kerosene. Sorbed oil recovered from sawdust and standard are $9.67 \mathrm{~g}$ of crude oil, $8.40 \mathrm{~g}$ of diesel, $6.50 \mathrm{~g}$ of kerosene and $2.90 \mathrm{~g}$ of crude oil, $2.50 \mathrm{~g}$ of diesel and $2.90 \mathrm{~g}$ of kerosene respectively. $2.60 \mathrm{~g}, 2.00 \mathrm{~g}$ and $1.30 \mathrm{~g}$ of sorbed crude oil, diesel and kerosene were retained by a unit mass of sawdust while $1.83 \mathrm{~g}, 1.94 \mathrm{~g}$ and $1.70 \mathrm{~g}$ of sorbed crude oil, diesel and kerosene were retained by a unit mass of the standard. Adsorption isotherm and kinetic studies shows that the sorption process of crude oil, diesel and kerosene onto sawdust is by Langmuir model and intraparticle diffusion and liquid film diffusion mechanism were parts of the rate determining steps. Sawdust could be employed to clean oil spill on land and aqueous environment. Sawdust is not a very effective oil spill clean-up sorbent, but can be useful when oil recovery is not required but disposal after oil spill clean-up.
\end{abstract}

\section{DOI: https://dx.doi.org/10.4314/jasem.v22i1.7}

Copyright: Copyright $@ 2017$ Kelle. This is an open access article distributed under the Creative Commons Attribution License (CCL), which permits unrestricted use, distribution, and reproduction in any medium, provided the original work is properly cited

Dates: Received 03 August 2017; received in revised form 16 December 2017; accepted 31 December 2017

Keywords: Sawdust, crude oil, adsorption kinetics, oil sorption capacity, sorbed oil recoverability, adsorption isotherm.

Key methods available for combating oil spill include mechanical containment method, chemical and biological methods, and physical methods. Mechanical method uses equipment that capture and store spilled oil until it can be disposed properly. Equipment used to contain and recover oil includes booms, barriers, skimmers and sorbents. Sorbents are insoluble materials or mixture of materials used to recover liquids through the mechanism of absorption, or adsorption, or both, and they can be natural or synthetic (Thomas, 2010). Natural materials are cheap, relatively in abundance, renewable and biodegradable.

Sawdust, a product of saw milling industries, is produced in very large quantities in most developing nations, consequent to the ever rising demand for furniture and building materials (El-ladan and Olofin, 2013). Deciduous rainforest areas in Nigeria, characterized by high rate of lumbering activities are faced with the menace of sawdust waste disposal (Oteraku and Ogedengbe, 2013). Virtually all sawmills therein are located along the river banks, and disposal of the sawdust waste is by the river side, where sometimes it is burnt. This action releases carbon dioxide to the atmosphere, resulting in environmental air pollution. However due to the constant rainfall in the region, burning is often terminated, consequently increasing the concentration of heaps of sawdust which seriously encroach into the river as suspended solids reducing the width of the river and invariably becoming a nuisance to the aquatic environment. Saw dust is used as a fuel, particleboard; coarse sawdust may be used for wood pulp. However saw dust is still underutilized, its usage can be expanded by putting it into further usage as in using it to produce sorbent for the oil industry. The assessment or performance of sorbing materials often needs to be compared (Volesky, 2004). This helps in efficient application of sorbents. Efficient application of sorbents requires knowledge of data on the sorbent sorption capacity and a good understanding on the basic mechanism behind the sorption capabilities (Singh et al, 2013). This study aims at determining oil sorption capacity, sorbed oil recoverability and retainability of sorbed oil, sorption mechanism of sawdust and if sawdust can be used for oil spill clean-up both on land and aqueous environment, and then compare these parameters with that of a standard; conventional synthetic sorbent used in the oil industry to clean oil spill.

\section{MATERIALS AND METHODS}

Sample Collection and preparation: Sawdust was obtained from a timber factory (sawmill factory) located at Head bridge, Onitsha, Anambra state, Nigeria. Crude oil and synthetic sorbent mat used as standard in the study were obtained from Shell

*Corresponding Author: henriettachima@yahoo.com 
Petroleum Development Company, Warri, Delta state, Nigeria and Shell Petroleum Development Company, Port Harcourt, Rivers State, Nigeria respectively. Diesel and kerosene were purchased from a filling station located in Asaba, Delta state Nigeria. The sawdust was ground using a mechanical blender and sieved through a sieve of $500 \mu \mathrm{m}$ (35 mesh) and packaged in pre-cleaned containers.

Determination of Equilibrium Sorption Capacity of Crude Oil, Diesel and Kerosene onto Sawdust and Synthetic Sorbent Mat: $1 \mathrm{dm}^{3}$ of crude oil, diesel and kerosene whose weight had been predetermined were each put in a pre-cleaned $2 \mathrm{dm}^{3}$ beaker. The weight of each sorbate was used as the initial concentration of each sorbate. Five (5) g of sawdust/synthetic sorbent mat was weighed and added into the beaker and left for a required contact time at $28^{\circ} \mathrm{C}$. The contact times used in this study ranged from 10 to 100 minutes, at 10 minutes interval. At the end of each contact time, the content in the beaker was passed through a sieve of $425 \mu \mathrm{m}$ into another pre-cleaned and pre-weighed $2 \mathrm{dm}^{3}$ beaker and allowed to drain. The weight of the $2 \mathrm{dm}^{3}$ beaker containing unsorbed sorbate was weighed and the weight of unsorbed sorbate obtained by weight difference. The weight of the unsorbed sorbate was used as final concentration of each sorbate. At each contact time the amount of crude oil, diesel and kerosene sorbed onto a unit mass of sawdust/synthetic sorbent mat was calculated from:

$$
q=\frac{C_{i-C_{f}}}{M}
$$

Where $\mathrm{q}=$ the amount of oil sorbed onto a unit mass of sawdust/synthetic sorbent mat, $C_{i}=$ initial concentration of oil in grams $(\mathrm{g}), C_{f}=$ final concentration of oil in grams $(\mathrm{g}), \mathrm{M}=$ mass of sorbent in grams $(\mathrm{g})$.

Determination of Equilibration time of Sorption of Crude Oil, Diesel and Kerosene onto Sawdust and Synthetic Sorbent Mat: This was obtained from the plot of amount of oil sorbed onto a unit mass of sawdust/synthetic sorbent mat against time, as the time corresponding with the amount of oil sorbed onto a unit mass of sawdust/synthetic sorbent mat at equilibrium.

Determination of Recovery of Sorbed Crude Oil, Diesel and Kerosene from Sawdust/Synthetic Sorbent Mat: The amount of sorbed crude oil, diesel and kerosene recovered from sawdust/synthetic sorbent mat was determined by removing each sorbent from the sieve, weighing it and afterwards subjecting it to pressing using a carver hydraulic press, Model M, serial No. $12000-137$, operated at a pressure of 25 tonnes, for five minutes, at $28{ }^{\circ} \mathrm{C}$. After pressing, the sorbent was re- weighed; the weight of sorbate recovered was determined by weight difference.

The amount of sorbed crude oil, diesel and kerosene recovered per unit mass of sawdust/synthetic sorbent mat was determined from the expression:

$$
q=\frac{\text { Initial weight }- \text { Final weight }}{\text { Mass of sorbent }}
$$

The experiment was performed in triplicate, the average and standard deviation were calculated and used. The amount of sorbed oils retained per unit mass of sawdust/synthetic sorbent mat was obtained from the expression: $\mathrm{q}=$ Quantity of oil sorbed per unit mass of sawdust/synthetic sorbent mat- Quantity of sorbed oil recovered per unit mass of sawdust/synthetic sorbent mat.

Determination of the sorption Process of Crude Oil, Diesel and Kerosene onto Sawdust/Synthetic Sorbent Mat Using Adsorption Isotherm.: The adsorption models applied to determine the sorption process of crude oil, diesel and kerosene onto sawdust/synthetic sorbent mat are the linearized form of Langmuir and Freundlich adsorption models.

The Langmuir equation may be written as:

$q_{e}=\frac{q_{m} b c_{e}}{1+b c_{e}}$

Where: $q_{e}$ is the amount of solute adsorbed per unit weight of sorbent at equilibrium $(\mathrm{mg} / \mathrm{g}), C_{e}$ is the equilibrium concentration of the solute in the bulk solution $\left(\mathrm{mg} \mathrm{L}^{-1}\right), q_{m}$ is the maximum adsorption capacity $(\mathrm{mg} / \mathrm{g}), \quad$ b is the constant related to the energy of adsorption and temperature, and affinity between the sorbent and sorbate (Langmuir, 1916).

Langmuir isotherm model can be linearized to five different forms, out of which the forms $\frac{1}{q_{e}}=\frac{1}{b q_{m}}$ $\frac{1}{C_{e}}+\frac{1}{q_{m}}\left(\right.$ plot $\frac{1}{q_{e}}$ vs. $\left.\frac{1}{C_{e}}\right)$ and $\frac{C_{e}}{q_{e}}=\frac{1}{q_{m C_{e}}}+\frac{1}{q_{m b}}\left(\right.$ plot $\frac{C_{e}}{q_{e}}$ $\operatorname{vs} C_{e}$ ) are the most frequently used by several researchers because of the minimized deviations from the fitted equation resulting in the best error distribution. A plot of $\frac{C_{e}}{q_{e}}$ against $C_{e}$ produces a linear graph with slope $=\frac{1}{q_{m}}$ and intercept $\frac{1}{k_{a q_{m}}}$ and a plot of $\frac{1}{q_{e}}$ versus $\frac{1}{C_{e}}$ gives a linear graph with slope $=\frac{1}{K_{a q_{m}}}$ and intercept $\frac{1}{q_{m}}$. Both linear forms were applied to the experimental data obtained. The Freundlich equation (Freundlich, 1906) can be written as: 


$$
q_{e}=k_{f} C_{e}^{1 / n}
$$

$K_{f}$ is a constant indicative of the relative adsorption capacity of the adsorbent $m g\left(^{1-(1 / n)}\right) \mathrm{L}^{1 / \mathrm{gg}-1}$ and $\mathrm{n}$ is a constant indicative of the intensity of the adsorption.

The linear model of Freundlich isotherm can be expressed logarithmically as:

$$
\log q_{e}={ }_{n}^{1} \log C_{e}+\log K_{f} \text { or } \ln q_{e}=\ln K_{f}+\frac{1}{n} \ln C_{e} .
$$

Both linear forms were applied to the experimental data obtained. The values of parameters $K_{f}$ and $1 / n$ can be determined from the intercept and slope of the plot $\log q_{e}$ against $\log C_{e}$ or $\ln q_{e}$ against $\ln C_{e}$ (Hamdaoui and Naffrechoux, 2007; Wei-Hong et al, 2013; Piccin et al, 2011). Usually to obtain experimental data to be fitted into an adsorption model, different initial concentrations of the sorbate and /or different mass of the sorbent is used during the experiment, so as to produce other values of equilibrium sorption capacity $\left(\mathrm{q}_{\mathrm{e}}\right)$ and equilibrium concentration $\left(\mathrm{C}_{\mathrm{e}}\right)$ at the end of the experiment. Five different initial concentrations of crude oil, diesel and kerosene were used to obtain different values of equilibrium sorption capacity $\left(\mathrm{q}_{\mathrm{e}}\right)$ and equilibrium concentration $\left(\mathrm{C}_{\mathrm{e}}\right)$. The experiment was conducted as mentioned above. The sorbate - sorbent system was left to contact for one hour. The experiment was conducted in triplicate for each initial concentration and the average taken.

Kinetic Studies: Lagergren pseudo-first-order and pseudo-second-order were the kinetic models applied to the experimental data to investigate the rate and mechanism of crude oil, diesel and kerosene sorption onto sawdust and synthetic sorbent mat.

The linearized pseudo-first-order kinetic model, which is also known as the Lagergren equation, can be expressed as:

$\ln \left(\mathrm{q}_{\mathrm{e}}-\mathrm{q}_{\mathrm{t}}\right)=\ln \mathrm{q}_{\mathrm{e}}-\mathrm{k}_{1} \mathrm{t}$

where $q_{\mathrm{t}}$ and $q_{\mathrm{e}}$ are the amounts of sorbate sorbed at time $t(\mathrm{~s})$ and equilibrium, respectively, in $\mathrm{mg} / \mathrm{g} . k_{1}$ is the pseudo-first-order rate constant $\left(\mathrm{s}^{-1}\right)$ (Dawodu and Akpomie, 2014). The slope and intercept of the plots of $\ln \left(q_{\mathrm{e}}-q_{\mathrm{t}}\right)$ as a function of $t$ were used to determine the rate constant and $q_{\mathrm{e}}$. The linear form of pseudo - second order kinetic model is expressed as:

$\frac{t}{q_{t}}=\frac{1}{k_{2 q_{e}^{2}}^{2}}+\frac{t}{q_{e}}$
Where $k_{2}$ is the rate constant of the pseudo-secondorder expression $\left(\mathrm{g} / \mathrm{mg} \mathrm{s}^{-1}\right)$. The $q_{\mathrm{e}}$ and $k_{2}$ values were calculated from the slope and intercept of the linear plot of $t / q_{\mathrm{t}}$ as a function of the time (t) (Ho and Mackay, 1998). The initial sorption rate $\mathrm{h}\left(\mathrm{mg} / \mathrm{g} \mathrm{s}^{-1}\right)$ ) was calculated from the following equation:

$\mathrm{h}=\mathrm{K}_{2} \mathrm{q}_{\mathrm{e}}^{2}$

Determination of Sorption of Crude Oil, Diesel and Kerosene Displaced on Water, Onto Sawdust and Synthetic Sorbent Mat; To ascertain the mopping behaviour of sawdust and synthetic sorbent mat when crude oil, diesel and kerosene spill on water, the experiment was repeated. 1 (one) $\mathrm{dm}^{3}$ of water was poured into a pre-weighed $2 \mathrm{dm}^{3}$ beaker and weighed; the weight of water was obtained by difference in weight. $0.5 \mathrm{dm}^{3}$ of oil whose initial weight had been predetermined was added into the water in the beaker. Five grams of sawdust/synthetic sorbent mat was weighed and added into the oil/water mixture and left for a contact time of 100 minutes.

Fourier Transform Infrared (FTIR) Spectroscopic Analysis of Standard (Conventional Synthetic Sorbent Mat); The functional groups present in the standard were determined by FTIR spectroscopy. The FTIR analysis was carried out using SHIMADZU FTIR8400S spectrophotometer with a $\mathrm{NaCl}$ cell.

\section{RESULTS AND DISCUSSION}

Fig. 1 presents the amount of crude oil, diesel and kerosene sorbed onto sawdust and the standard. From the figures, the equilibrium sorption capacity of the sorbates onto sawdust, which is the oil sorption capacity of sawdust, is $5.50 \mathrm{~g}$ of crude oil at 80 minutes, $4.50 \mathrm{~g}$ of diesel at 90 minutes and $4.20 \mathrm{~g}$ of kerosene at 90 minutes. The equilibrium sorption capacity of the sorbates onto synthetic sorbent mat is $11.50 \mathrm{~g}$ of crude oil at 40 minutes, $10.35 \mathrm{~g}$ of diesel at 60 minutes and $8.20 \mathrm{~g}$ of kerosene at 40 minutes. The result shows that the synthetic sorbent sorbed more of the oils than sawdust, indicating that it has higher oil sorption capacity than sawdust.

Several factors contribute to sorption, and these include high surface area and highly reactive sorbates and sorbents; organic sorbates chemically bond to the sorbent, if the sorbate and sorbent have mutually reactive moieties (Brown, 1983).

Variety of different types of attractive forces between the sorbate and sorbent results in sorption and the extent of these intermolecular attractions depends on molecular chain length and on surface area available for interaction (Weber et al, 1991). 
Sawdust is composed of fine particle of wood. Wood is essentially composed of cellulose $(40 \%)$, hemi cellulose $(17 \%)$ and lignin $(33 \%)$ (Sjoostrom and Alen, 1993; Usia and Karfa, 1997).Sawdust contains cellulose, hemicellulose and lignin; cellulose consists of subunits of D-pyran glucose with $\beta-1$, 4glucosidic bonds between the subunits, hemicellulose consist of subunits of D-Xylose, mannose, Larabinose, galactose and glucuronic acid while lignin consist of subunits of guaiacylpropane, syringyl propane and hydroxylphenylpropane with various ether bonds and carbon - carbon, mainly $\beta-\mathrm{O}-4$ ether bond between the subunits (Santos Cabral et al, 2016; Chen, 2014). FTIR spectrum of the synthetic sorbent mat is shown in Fig. 2, the prominent peaks indicates that it is a polyhydrocarbon; $829.42 \mathrm{~cm}^{-1}$ (s) C-H of alkene, $983.73 \mathrm{~cm}^{-1}$ (s) C-H of alkene, $1159.26 \mathrm{~cm}^{-1}$, (s) C-C of alkane, $1369.50 \mathrm{~cm}^{-1}$ (s) C-H of alkane , $1453.41 \mathrm{~cm}^{-1}$ (s) C-H of alkane, $2925.15 \mathrm{~cm}^{-1}$ (s) C-H of alkane.

The synthetic sorbent mat and the sorbates are composed mainly of hydrocarbons; in order words they have mutual reactive moieties than sawdust with the sorbates, hence will interact better than with sawdust. This explains partly why the more oil sorption capacity of the synthetic sorbent mat.

The time at which the sorbents attained sorption equilibrium in each of the sorbates indicates that the standard (40 minutes) attained equilibrium at a lesser time compared with sawdust (90 minutes). This can be attributed to the standard having large internal surface area and wide pore volume distribution which enabled faster oil uptake by the standard.

The sorption of the sorbates onto sawdust and the synthetic sorbent increased as the sorption time increased until equilibrium was attained because three consecutive mass transport steps are associated with the sorption of a solute from solution by a porous sorbent (Faust and Aly, 1983). First, the solute migrates through the solution to the external surface of the sorbent particles by molecular diffusion (film diffusion), followed by solute movement from particle surface to interior sites (pore diffusion) and finally the solute absorbed onto these sites, this makes the sorption gradual. Result also indicates that sorption capacity in both sawdust and the standard increased with increase in viscousity of the sorbates. Viscousity increases as chain length increases.

As chain length increases in a hydrocarbon, its surface area increases. This gives rise to increased intermolecular attraction. As intermolecular attraction increases, sorption increases. Sorbents can be compared by their respective maximum adsorption capacity $q_{m}$ and b values obtained from the Langmuir equation (Volesky, 2004).

The maximum adsorption capacity $q_{m}$ is obtained from the isotherm model while $q_{e}$ is the equilibrium adsorption capacity obtained from experiment (Jing et al, 2010). $q_{m}$ can be interpreted as the total number of binding sites that are available for sorption, and $q_{e}$ as the number of binding sites that are in fact occupied by the sorbate at the equilibrium concentration $C_{e}$ (Volesky, 2004).

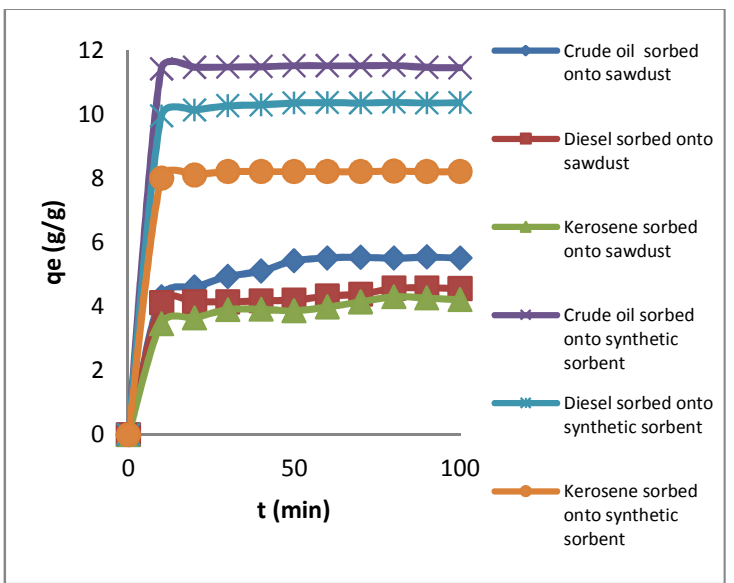

Fig 1: Amount of crude oil, diesel and kerosene sorbed onto a unit mass of sawdust/ synthetic sorbent mat against time.

The linearized form $C_{e} / q_{e}$ versus $C_{e}$ of the Langmuir adsorption isotherm produced the best fit isotherm (0.999) for the sorption of crude oil, diesel and kerosene onto sawdust and synthetic sorbent, this result is presented in Fig. 3. This indicates that the sorption process follows the Langmuir isotherm, which implies that the interaction of both sorbents with the sorbates is monolayer adsorption, that is, one sorbate molecule is adsorbed on a layer of sorbent and there is no interaction between sorbed molecules.

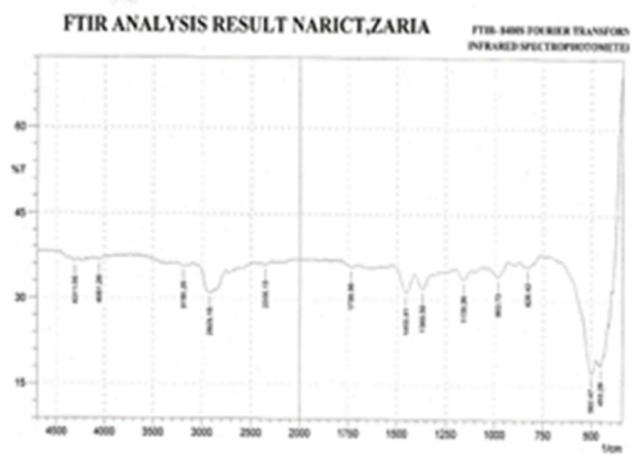

Fig 2: FTIR spectrum of synthetic sorbent mat. 
The constant $\mathrm{b}$ and $q_{m}$ are obtained from the slope and interception of the plot and are presented in Table 1 , the $b$ values obtained for sawdust is lower than that obtained for synthetic sorbent mat. This implies that the synthetic sorbent mat has greater affinity for the sorbates than saw dust. Table 1 show that the calculated maximum adsorption capacity value $\left(q_{m}\right)$ of sawdust and the synthetic sorbent mat are slightly higher than their experimental equilibrium adsorption capacity value. This further show that Langmuir isotherm provides better fit to the experimental values and can be used to verify the adsorption of crude oil, diesel and kerosene onto sawdust and synthetic sorbent mat. The higher $q_{m}$ values of synthetic sorbent mat compared with those of sawdust indicates that synthetic sorbent mat has more total number of binding sites than sawdust, which implies that, the synthetic sorbent mat has a larger surface area than sawdust. This explains why synthetic sorbent sorbed more oil than sawdust. The $q_{m}$ and b values of sawdust and synthetic sorbent mat shows that the synthetic sorbent mat is a better sorbent than sawdust. The favourable nature of adsorption and affinity between the sorbate and sorbent can be expressed in terms of dimensionless separation factor equilibrium parameter of Hall et al, 1966 which is defined by the following relationship, $K_{R=1 / 1}+K_{a} C_{o}$, where $K_{R}$ is a dimensionless separation factor, $C_{o}$ is initial concentration $\left(\mathrm{mg} \mathrm{L}^{-1}\right)$ and $K_{a}$ is Langmuir constant $\left(\mathrm{L} \mathrm{mg}^{-1}\right)$. The values of $K_{R}$ indicates the type of isotherm to be irreversible $\left(K_{R}=0\right)$, favourable $\left(0<K_{R}<1\right)$, linear $\left(K_{R}=1\right)$ or unfavourable $\left(K_{R}>1\right)$. The dimensionless separation factors calculated for sawdust and synthetic sorbent mat are presented in tables 1 . The $K_{R}$ values were less than 1 and greater than zero indicating favourable adsorption.

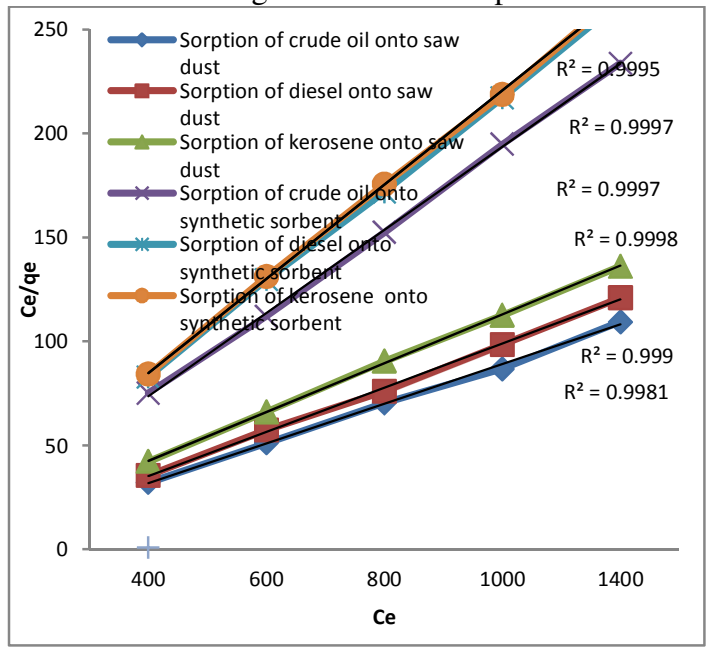

Fig 3: Langmuir Ce/qe versus Ce of sorption of crude oil, diesel and kerosene onto sawdust/synthetic sorbent mat.
$2.90 \mathrm{~g}$ of crude oil (53\% of sorbed crude oil), $2.50 \mathrm{~g}$ of diesel (56\% of sorbed diesel) and $2.90 \mathrm{~g}$ of kerosene (69\% of sorbed kerosene) were recovered from a unit mass of sawdust while $9.67 \mathrm{~g}$ of crude oil ( $84 \%$ of sorbed crude oil), $8.40 \mathrm{~g}$ of diesel (81\% of sorbed diesel) and $6.50 \mathrm{~g}$ of kerosene (79 \% of sorbed kerosene) were recovered from a unit mass of synthetic sorbent mat. More of the sorbed oils were recovered from the standard than sawdust; this shows that the standard has higher sorbed oil recoverability than sawdust, which may be attributed to the standard been composed of porous structure of large internal surface area and wide pore volume distribution, therefore more sorbates diffuse into the pores and effuse easily than in sawdust. The amount of sorbed oils retained by a unit mass of sawdust is about $2.60 \mathrm{~g}$ of crude oil (47 \% of sorbed crude oil), $2.00 \mathrm{~g}$ of diesel (44\% of sorbed diesel), and $1.30 \mathrm{~g}$ of kerosene (31\% of sorbed kerosene), while, $1.83 \mathrm{~g}$ of crude oil (15\% of sorbed crude oil), 1.94g of diesel (19\% of sorbed diesel) and $1.70 \mathrm{~g}$ of kerosene (20\% of sorbed kerosene) were retained by a unit mass of synthetic sorbent mat. The percentage value reveals that sawdust retained more of the sorbed oils than the synthetic sorbent mat, this indicates that it has higher sorbed oil retainability than the standard and it is suitable for removal of the sorbates; since one of the features of a good sorbent is high degree of oil retention (Volesky, 2004; Hoskin, 2006), especially when clean-up does not require recovery but disposal.

The result of kinetic studies of the rate and mechanism of sorption of crude oil, diesel and kerosene onto sawdust and synthetic sorbent mat is presented in Table 1. The result suggests that the sorption of crude oil, diesel and kerosene onto sawdust and synthetic sorbent mat is not a first order reaction. The pseudo first order kinetic model correlation coefficients $\left(\mathrm{R}^{2}\right)$ value is low for sorption of the sorbates onto sawdust. However, it is higher for synthetic sorbent but the pseudo second order kinetic model correlation coefficients $\left(\mathrm{R}^{2}\right)$ value of the sorption of the sorbates onto synthetic sorbent mat is higher than it. Moreover the calculated equilibrium sorption capacities of both sorbents are lower than the experimental values this implies that the sorption of crude oil, diesel and kerosene onto sawdust and the synthetic sorbent mat is not a first order reaction.

Pseudo second order kinetic model correlation coefficient $\left(\mathrm{R}^{2}\right)$ and calculated equilibrium adsorption capacities $\left(q_{e}\right.$ calc) values of the sorption of the oils onto sawdust and synthetic sorbent mat are presented in Figure 5 and Table 1 . The $\mathrm{R}^{2}$ values are between $0.997-0.999$, indicating that sorption of the oils onto 
the sorbents fits pseudo-second order kinetics. $\mathrm{q}_{\mathrm{e}}$ calc of each oil onto the sorbents is higher than the experimental values (table 1), showing the fit of pseudo- second order mechanism for the sorption of crude oil, diesel and kerosene onto sawdust and synthetic sorbent mat. This implies chemisorptions took place during the sorption process. This indicates that when the oils get to the surface of the sorbents due to the driving force obtained from the high concentration of the oils, it encounters fewer active sites or functional groups on the surface to be adsorbed. The high concentration of the oils on the surface then pushes the adsorbed oils from the surface through the pores (intraparticle diffusion) to the internal sites of the sorption. The amount of water sorbed together with each sorbate onto sawdust and synthetic sorbent mat in the experiment to determine suitable environment applicability of sawdust and the standard was $13 \mathrm{ml}(2.7 \mathrm{~g})$ for sawdust and $6 \mathrm{ml}(1.2$ g) for the standard. These amounts are minimal for each of the sorbent, but more minimal for the synthetic sorbent mat, indicating that sawdust could be employed to mop oil spill on water.

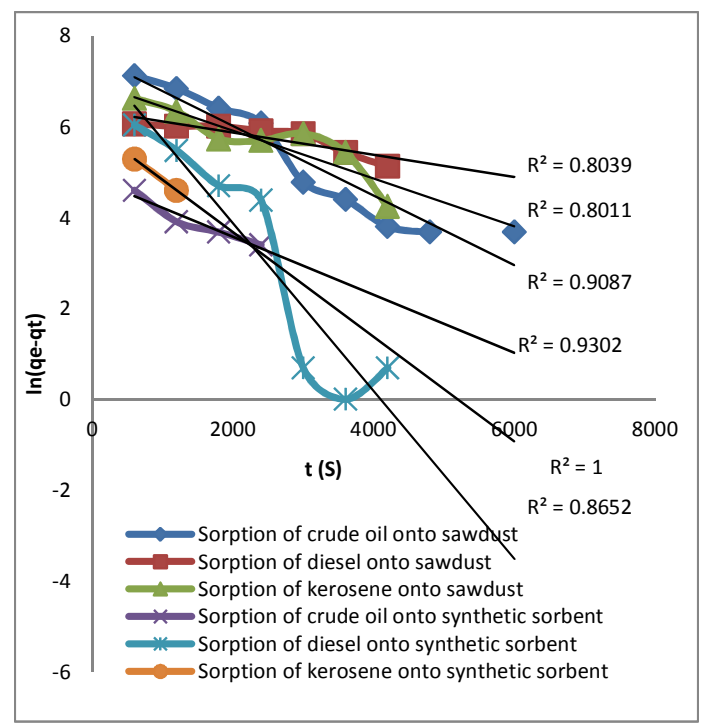

Fig 4: Pseudo first order $\operatorname{lnq}_{\mathrm{e}}-\mathrm{q}_{\mathrm{t}}$ versus $\mathrm{t}$ of sorption of crude oil, diesel and kerosene onto sawdust/synthetic sorbent mat.

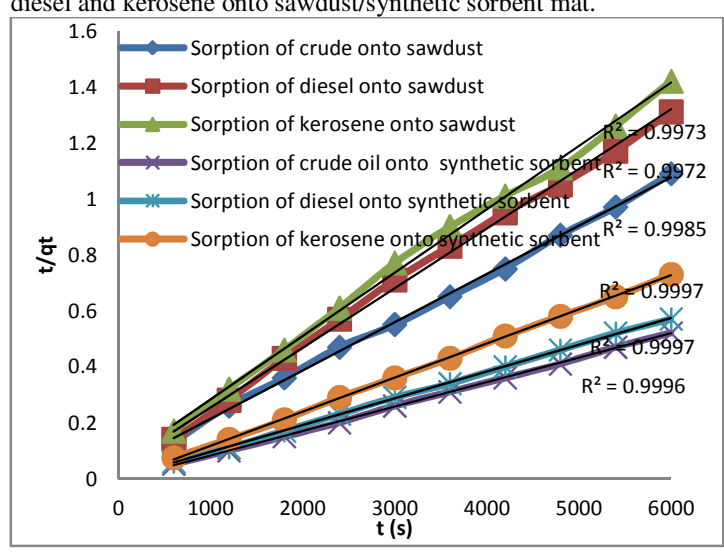

Fig 5: Pseudo second order $t / q_{t}$ versus $t$ of sorption of crude oil, diesel and kerosene onto sawdust/synthetic sorbent mat.

Conclusion: Sawdust has lesser oil sorption capacity and sorbed oil recoverability than standard, but has higher sorbed oil retainability than standard. The sorption of crude oil, diesel and kerosene onto sawdust is by Langmuir adsorption model. Intraparticle diffusion model and liquid film diffusion model were parts of the rate determining steps of the sorption process of the oils onto sawdust. Sawdust can be applied on land and aqueous environment in oil spill clean-up. Sawdust is not a very effective oil spill sorbent, but can be useful when oil recovery is not required but disposal after oil spill clean-up exercise.

Table 1: Parameters of Langmuir isotherm $\left(\mathrm{C}_{\mathrm{e}} / \mathrm{q}_{\mathrm{e}} \mathrm{vs} \mathrm{C}_{\mathrm{e}}\right)$, equilibrium sorption capacity $\left(\mathrm{q}_{\mathrm{e}}\right)$ Pseudo first and second order of crude oil, diesel

\begin{tabular}{|c|c|c|c|c|c|c|}
\hline Sorption type & $b\left(\mathrm{~L} \mathrm{~g}^{-1}\right)$ & $q_{m}\left(\mathrm{~g} \mathrm{~g}^{-1}\right)$ & $q_{e}\left(\mathrm{~g} \mathrm{~g}^{-1}\right)$ & $q_{\mathrm{e}, \exp }(\mathrm{mg} / \mathrm{g})$ & $\mathrm{q}_{\mathrm{e}, \mathrm{Calc}}(\mathrm{mg} / \mathrm{g})$ & $\mathrm{q}_{\mathrm{e}}$, Calc $(\mathrm{mg} / \mathrm{g})$ \\
\hline $\begin{array}{l}\text { Sorption of crude oil onto } \\
\text { saw dust }\end{array}$ & -2.00 & 5.60 & 5.50 & 5500 & 199.8 & 6250 \\
\hline $\begin{array}{l}\text { Sorption of diesel onto } \\
\text { saw dust }\end{array}$ & -2.00 & 4.80 & 4.50 & 4500 & 419.89 & 5000 \\
\hline $\begin{array}{l}\text { Sorption of kerosene onto } \\
\text { saw dust }\end{array}$ & -2.00 & 4.35 & 4.20 & 4200 & 1096 & 4545 \\
\hline $\begin{array}{l}\text { Sorption of crude oil onto } \\
\text { synthetic sorbent }\end{array}$ & 1.00 & 11.62 & 11.50 & 11500 & 121.51 & 12500 \\
\hline $\begin{array}{l}\text { Sorption of diesel onto } \\
\text { synthetic sorbent }\end{array}$ & 1.00 & 10.52 & 10.35 & 10350 & 735.09 & 10880 \\
\hline $\begin{array}{l}\text { Sorption of kerosene onto } \\
\text { synthetic sorbent }\end{array}$ & 1.00 & 8.40 & 8.20 & 8200 & 365.03 & 8333.33 \\
\hline
\end{tabular}




\section{REFERENCES}

Brown, GI (1983). Introduction to Physical Chemistry. Longman, London.

Chen, H (2014). Biotechnology of Lignocellulose. Springer, Netherlands.

El-ladan, IY; Olofin, EA (2013). Evaluation of Various Chemical Treatments of Sawdust as a Replacement for Wheat Offal in Feeding Goat (capra prisca). Int. J. P. Appl. Sci.Technol. 19(1):70-74.

Faust, DC; Aly, MO (1983). Chemistry of Wastewater Treatment. Butterworth, London.

Freundlich, HMF (1906). Uber Die Adsorption in Losungen. Z. Phys. Chem. 57: 385- 470. In Hamdaoui, O, Naffrechoux, E (2007). Modelling of Adsorption Isotherms of Phenol and Chlorophenols onto Granular Activated Carbon Part 1. Two-Parameter Models and Equations Allowing Determination of Thermodynamic Parameters. J. Hazard Mater. 17(147):381-394.

Hamdaoui, O, Naffrechoux, E (2007). Modelling of Adsorption Isotherms of Phenol and Chlorophenols onto Granular Activated Carbon Part 1. Two-Parameter Models and Equations Allowing Determination of Thermodynamic Parameters. J. Hazard Mater. 17(147):381-394.

Ho, YS; Mackay, G (1998). The Kinetics of Sorption of Basic Dyes from Aqueous Solution

By Sphagnum Moss Peat, Can. J. Chem. Eng. 76(4): 822-827.

Hoskin, MG; Underwood, AJ; Archambault, P (2006). Properties of Naturally Degrading Sorbents for Potential Use in the Clean-up of Oil Spill in Sensitive and Remote Coastal Habitat, Centre for Research on Ecological Impacts of Coastal Cities, Marine Ecology Laboratories (ALL). University of Sydney.NSW 2006. Final Report for AMSA; 2001. https://en.wikipedia.org/wiki/Sawdust. Retrieved 4/3/2017

Jing, H; Song, H; Liang, Z; Fuxing, G; Yuhshan, H (2010). Equilibrium and Thermodynamic Parameters of Adsorption of Methylene Blue onto Rectorite. Fresenius Env. Bull. 19(11a):2651-2656.
Langmuir, I (1916). The Constitution and Fundamental Properties of Solids and Liquids. J. Am. Chem. Soc. 38:2221- 2295. In: Hamdaoui, O, Naffrechoux, E (2007). Modelling of Adsorption Isotherms of Phenol and Chlorophenols onto Granular Activated Carbon Part 1. Two-Parameter Models and Equations Allowing Determination of Thermodynamic Parameters. J. Hazard Mater. 17(147):381-394.

Oteraku, I J; Ogedengbe, EV (2013). Biogas Production from Sawdust Waste, Cow Dung and Hyacinth- Effect of Sawdust Concentration. Int. J. Appli. Innov. Eng. \& Mgt

2(6):1-7.

Santos Cabral, MM; De Souza Abud, AK; De Farias Silva, CE; Garcia Almeida, RM (2016). Bioethanol Production from Coconut Husk Fiber. Cienc. Rural 46(10): 1-7.

Piccin, JS; Dotto, GL; Pinto, LAA (2011). Adsorption Isotherms and Thermochemical Data of FD\&C Red $n^{\circ} 40$ Binding by Chitosan. Braz. J. Chem. Eng. 28 (2):1-6.

Singh, V; Kendall, RJ; Hake, K; Ramkumar, S (2013). Crude Oil Sorption by Raw Cotton. Ind. Eng. Chem. Res. 52(18): 6277 - 6281.

Sjoostrom, E; Alen, R (1993). Analytical Methods in Wood Chemistry, Pulping and Paper Making, Springer, Chicargo.

Thomas, PW (2010). Sorbents, Properties, Materials and Application, Nova Science, N. Y.

Usia, M; Karfa, S (1997). The Chemical Composition of Wood and Bark of Cedrus Libani A. Rich. Holz als Roh-und Werkstoff. 55(2): 268.

Volesky, BV (2004). Sorption and Biosorption. BV Sorbex, Montreal.

Wei-Hong, X; Lei, W; Jing, W; Guo-Ping, S; JinHuai, L; Han-Qing, Y; Xing-Jiu, H (2013). Superparamagnetic Mesoporous Ferrite Nanocrystal Clusters for Efficient Removal of Arsenite from Water. Cryst Eng Comm 15(39):7805-7903.

Weber, WJ; McGinley, PM; Katz, LE (1991). Sorption Phenomena in Subsurface Systems: Concepts, Models and Effects on Contaminant Fate and Transport. Wat. Res. 25: 499-528. 